\title{
Evolutionary Signature of Information Transfer Complexity in Cellular Membrane Proteomes
}

\author{
Jong-Min $\mathrm{Kim}^{1}$, Byung-Gee $\mathrm{Kim}^{1}$ and $\mathrm{S}$. June \\ $\mathrm{Oh}^{2 *}$
}

${ }^{1}$ School of Chemical and Biological Engineering, College of Engineering, Seoul National University, Seoul 151-742, Korea, ${ }^{2}$ Department of Pharmacology, College of Medicine and Ubiquitous Healthcare Research Center, Inje University, Busan 614-735, Korea

\begin{abstract}
Cell membrane proteins play crucial roles in the cell's molecular interaction with its environment and within itself. They consist of membrane-bound proteins and many types of transmembrane (TM) proteins such as receptors, transporters, channel proteins, and enzymes. Membrane proteomes of cellular organisms reveal some characteristics in their global topological distribution according to their evolutionary positions, and show their own information transfer complexity. Predicted transmembrane segments (TMSs) in membrane proteomes with HMMTOP showed near power-law distribution and frequency characteristics in 6-TMS and 7-TMS proteins in prokaryotes and eukaryotes, respectively. This reaffirms the important roles of membrane receptors in cellular communication and biological evolutionary history.
\end{abstract}

Keywords: chemoreceptor, G protein-coupled receptor, information transfer complexity, membrane protein topology, seven-transmembrane region, signal transduction, transmembrane protein

\section{Introduction}

With the availability of high-throughput biological data, great efforts have been expended to find universal features of DNA sequences in untranslated region (UTR) introns (Hong et al., 2006), 5'UTR (Lynch et al., 2005), 3'UTR, and coding exons (Martignetti and Caselle, 2007) to show a power-law distribution since long-range correlations in noncoding DNA sequence were first observed (Li and Kaneko, 1992; Peng et al., 1992; Voss, 1992). Gene family size in single genomes from archaea,

*Corresponding author: E-mail o@biophilos.org

Tel +82-51-893-3569, Fax +82-51-797-8569

Accepted 27 April 2009 bacteria, and eukaryota (Huynen \& van Nimwegen, 1998; Harrison \& Gerstein, 2002) also obey power-law distributions. Such distributions have been observed in many different types of networks such as the World Wide Web (Albert et al., 1999) and biological metabolic networks (Jeong et al., 2000). It seems that all of these observations are found to be consistent with the power law.

The evolutionary history of an organism involves the reactions of the organism to its environments over generations. In biological systems, the composition of proteins located in the cellular membrane determines the interaction of the cell with its environment and consequently how effectively it can communicate with its neighbors and adapt itself to the circumstances. To survive a changing environment, a species adds genes that have effects on beneficial phenotypes over generations. These effects strongly depend on other genes in the genome with which they cooperate.

Membrane proteins are the most important members of inter- and intracellular transduction of materials and information. They are predicted to constitute $20-30 \%$ of all the proteins in an animal's genome sequence (Wallin \& von Heijne, 1998; Krogh et al., 2001) and are essential for the organism's interaction with its environment. Proteins such as channel proteins and transporters drive the transmembrane movement of ions, solutes, and small molecules. Other proteins such as receptors receive signals by interacting with a large variety of ligands, including hormones, neurotransmitters, autacoids, chemokines, odorants, even light, and transduce them to various kinds of information. Membrane proteins with seven transmembrane segments (7-TMSs) play major roles in signal transformation and information transport in cellular organisms.

A wide variety of genomic and proteomic studies have been carried out since tens of whole genome sequences were determined. In 2003, a database of experimentally characterized transmembrane topologies was constructed and reported as TMPDB; it contained a total of 302 TM protein sequences (lkeda et al., 2003). Recently, the distributions of membrane protein topologies in both $\mathrm{E}$. coli and $\mathrm{S}$. cerevisiae membrane proteomes were reported (Daley et al., 2005; Kim et al., 2006). There were a very small number of 7-TMS proteins compared with the numbers of proteins with other TMS numbers in E. coli, whereas a larger number of 7-TMS proteins were found in S. cerevisiae. Instead, E. 
coli has shown more 6-TMS proteins than 5- and 7-TMS proteins in its proteome.

Polytopic proteins consist of various characteristic structures and functions according to their transmembrane domain. In proportion as the transfer complexity of cellular information increases, the number of membrane proteins involved in signal transduction may increase.

As a first step toward the exploration of topology distributions in the cellular membrane proteome, we now report the TMS distributions in the membrane proteomes from prokaryotic and eukaryotic organisms.

\section{Methods}

Many species genomes have been fully sequenced and annotated. In this study, 114 proteomes consisting of protein-coding genes from 46 prokaryotes (38 Eubacteria, 8 Archaea) and 72 eukaryotes were examined (Table $\mathrm{S} 1$ in supplementary material). Amino acid sequence data of protein-coding genes from 114 species were retrieved from public biological databases (Table S2 in supplementary material) and analyzed for the topology prediction of polytopic proteins. We used HMMTOP 2.1 (Tusnády \& Simon, 1998; Tusnády \& Simon, 2001) for the topology prediction of polytopic proteins. HMMTOP was based on parameters obtained by statistical analy- sis of protein sequence databases rather than those based on hydrophobicity measures. The method was implemented with hidden Markov models and is considered to show the best performance among TM topology-prediction methods (Ikeda et al., 2002; Inoue et al., 2005; Tusnády \& Simon, 2001). It is also suitable for the large-scale analysis of membrane protein topology.

Each protein-coding FASTA entry out of a species' whole proteome was analyzed by HMMTOP to produce an output file in the long format to count the TMS number of each entry. The HMMTOP results of protein-coding genes in each proteome were sorted and grouped into bundles according to the TMS number of each gene, using custom Python scripts. To assess the global relationship between TMS number and the corresponding protein number in the proteomes from all 114 species, we constructed a scatter plot. We also investigated the trends in the populations of TMS numbers from each species.

\section{Results and Discussion}

\section{TMS distribution in membrane proteomes}

The TMS number of each protein-coding gene was plotted logarithmically against the corresponding protein number in the proteome of each species to produce a

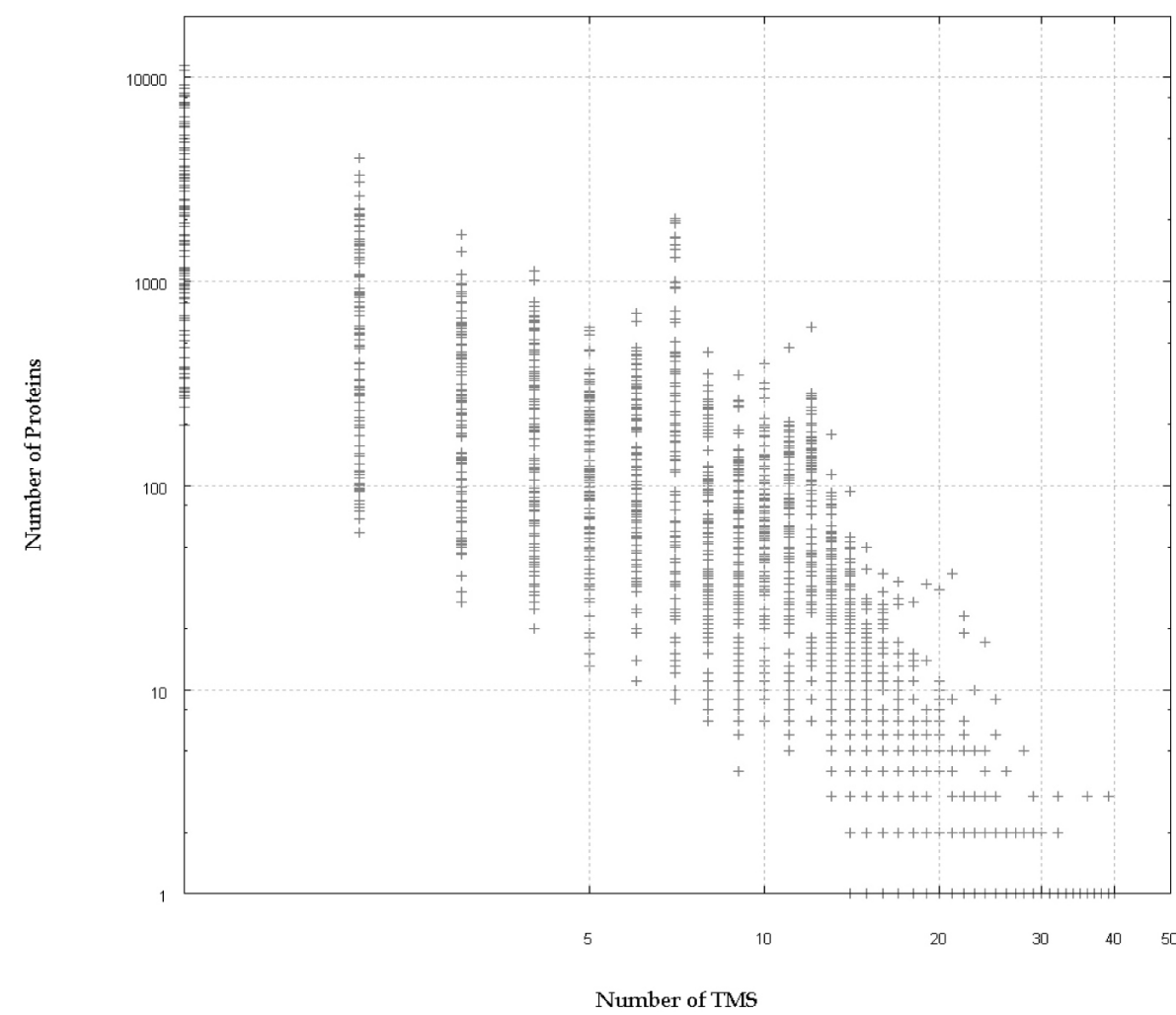

Fig. 1. Global TMS distribution in predicted cellular membrane proteomes. Each proteome from 114 species was plotted logarithmically with its TMS number and corresponding protein number. 
global topology distribution (Fig. 1). The overall TMS distribution in the proteomes of 114 species shows a power-law pattern similar to those of the other biological features mentioned previously.

Table 1 shows the list of biological classes for which protein-coding genes were analyzed and their tendency between the numbers of 7-TMS proteins and 6-TMS proteins.

We can see that there are more 7-TMS proteins than 6-TMS proteins in the higher eukaryotes, particularly with the exception of plants. The tendency was confused among some species of fungi (represented as

Table 1. Biological classes of 114 species included in the membrane proteome analysis and their tendency between the numbers of 7-TMSPs (7-transmembrane segment proteins) and 6-TMSPs

\begin{tabular}{lcclrl}
\hline $\begin{array}{c}\text { Biological } \\
\text { classes }\end{array}$ & $\begin{array}{c}\text { No. } \\
\text { Species }\end{array}$ & $7>6^{*}$ & $\begin{array}{c}\text { Biological } \\
\text { classes }\end{array}$ & $\begin{array}{c}\text { No. } \\
\text { Species }\end{array}$ & $7>6$ \\
\hline Mammalia & 18 & 0 & Metazoa & 1 & 0 \\
Aves & 1 & 0 & Fungi & 18 & $+^{* *}$ \\
Fish & 3 & 0 & Plants & 6 & $\mathrm{x}$ \\
Amphibia & 1 & 0 & Protists & 10 & $\mathrm{x}$ \\
Insects & 8 & 0 & Red/green algae 3 & $\mathrm{x}$ \\
Worm & 1 & 0 & Eubacteria & 38 & $\mathrm{x}$ \\
Deuterostome & 2 & 0 & Archaea & 8 & $\mathrm{x}$ \\
\hline
\end{tabular}

${ }^{*} 7>6$ : number of 7-TMSPs $>$ number of 6-TMSPs.

${ }^{* \star}+{ }^{\prime}$ ' represents the mixture of ' $O$ ' and ' $x$ '. (The list of species was provided as supplementary material).
' + ' in Table 1). Prokaryotes showed a different tendency in the distribution of TMS numbers.

To find characteristics in the plot, we examined the tendencies of the TMS distribution and found that a peculiar pattern of 7-TMS proteins appeared in the topological distribution of eukaryotic membrane proteomes. In Fig. 2, the numbers of proteins corresponding to each TMS number decreased rapidly until the TMS number reached six, and gave an asymptotic pattern to zero after eight, except at seven. In particular, in multicellular eukaryotic organisms, the number of 7-TMS proteins is much higher than that of 6-TMS proteins. Seven-TMS proteins in eukaryotic organisms consist mainly of membrane receptors functioning as key members in cellular signal transduction.

The ratio of 7-TMS protein number to that of whole proteins in an organism reveals a cross section of cellular information transfer complexity. To approximate information transfer complexity in an organism, we set an arbitrary number, namely the seven (zayin)-TMSP part score (zps), and it was calculated as:

$$
z p s=N_{(7-T M S P)}=N_{(T P G)},
$$

where $N_{(7-T M S P)}$ is the number of 7 -TMS proteins and $N_{(T P G)}$ is the total number of protein-coding genes in an organism. Similarly, we can also compute another arbitrary number, namely the six (vav)-TMSP part score (vps), which was calculated as:

$$
v P S=N_{(6-T M S P)}=N_{(T P G)},
$$

where $N_{(6-T M S P)}$ is the number of 6 -TMS proteins and
TMS distribution in eukaryotic membrane proteomes

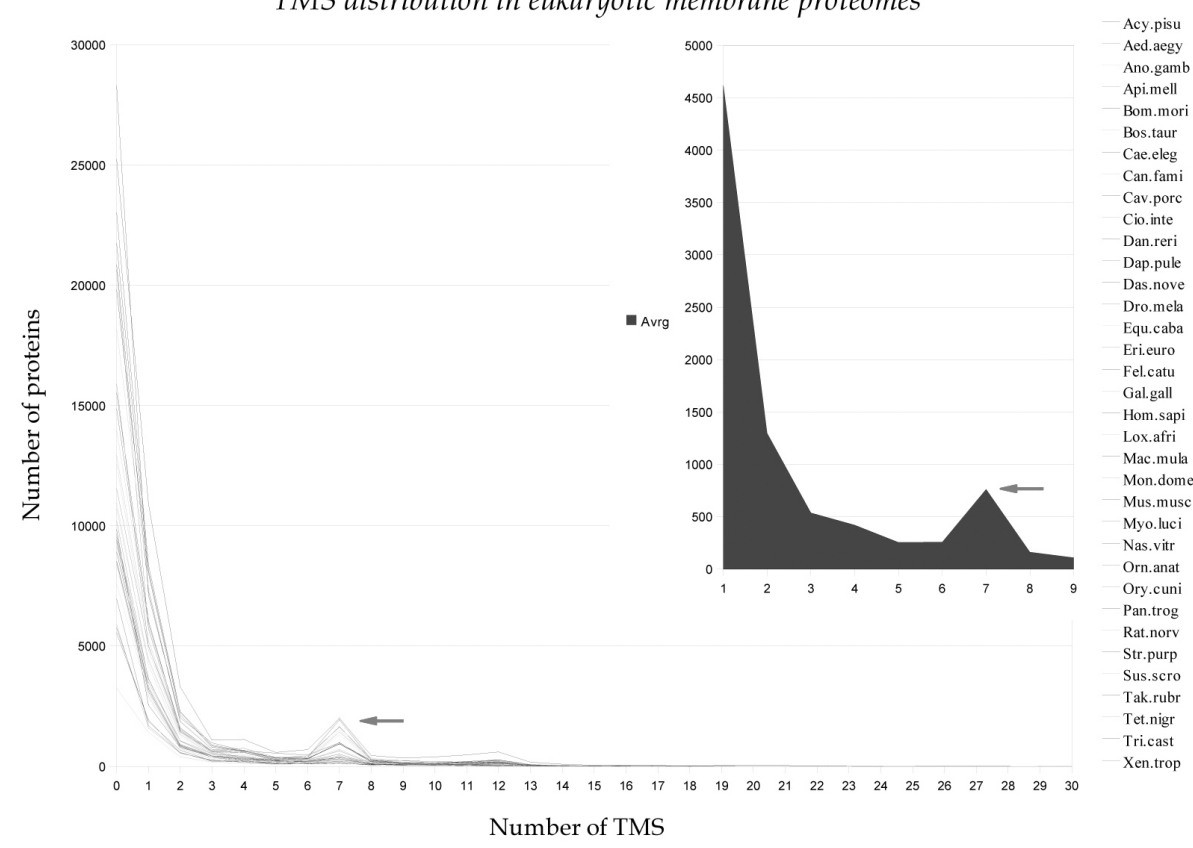

Fig. 2. TMS distribution in eukaryotic membrane proteomes from 35 species (Mammalia to Metazoa in Table 1). The numbers of 7-TMS proteins are indicated by red arrows. The small graph in dark blue shows the distribution pattern for the average value of each TMS number. 
Table 2. zpss and rzvs from selected species

\begin{tabular}{lcclcc}
\hline \multicolumn{1}{c}{ Species } & $z p s^{*}$ & $r z v^{*}$ & \multicolumn{1}{c}{ Species } & $z p s$ & $r z V$ \\
\hline E. caballus (horse) & 0.072 & 5.290 & C. intestinalis (vase tunicate) & 0.020 & 1.804 \\
B. taurus (cow) & 0.064 & 4.774 & D. pulex (water flee) & 0.009 & 1.555 \\
R. norvegicus (rat) & 0.062 & 5.201 & P. trichocarpa (poplar tree) & 0.007 & 0.728 \\
C. elegans (nematode) & 0.061 & 4.214 & V. carteri (Volvox, green alga) & 0.007 & 0.758 \\
X. tropicalis (Xenopus) & 0.059 & 3.724 & O. sativa (rice) & 0.007 & 0.763 \\
M. musculus (mouse) & 0.055 & 5.168 & G. max (soybean) & 0.006 & 0.780 \\
D. rerio (zebrash) & 0.035 & 2.994 & R. communis (castor oil plant) & 0.006 & 0.747 \\
H. sapiens (human) & 0.027 & 3.257 & M. truncatula (medick) & 0.004 & 0.873 \\
F. catus (cat) & 0.024 & 1.695 & S. cerevisiae (budding yeast) & 0.008 & 0.930 \\
G. gallus (chicken) & 0.024 & 1.802 & S. pombe (ssion yeast) & 0.009 & 1.158 \\
A. gambiae (mosquito) & 0.020 & 1.665 & E. coli (prokaryote) & 0.008 & 0.388 \\
D. melanogaster (fruit fly) & 0.018 & 1.545 & X. campestris (prokaryote) & 0.005 & 0.273 \\
\hline
\end{tabular}

${ }^{*} z p S: 7$ (zayin)-TMSP part score. ${ }^{* *} r z v$ : ration of $z($ ayin)ps/v(av)ps.

$N_{(T P G)}$ is the total number of protein-coding genes in an organism. We then calculated the ratio of zps to vps (rzv) as follows:

$$
r z v=z p s / v p s .
$$

$r z V$ values for motile multicellular organisms are all greater than 1.5 and most zpss of eukaryotes are higher than 0.010 , except for those of plants and fungi (Table 2 ). In all six tested plants, zps values were less than 0.007 . This may have resulted from the difference of connective systems between plants and animals.

In the taxonomic tree of 114 species, all 35 species in the branch of Bilateria in Metazoa group were shown to have more 7-TMS proteins than 6-TMS ones as shown in Fig. 2. Ten species among Fungi group except Saccharomycetaceae also showed rzv values just over 1.0 (Fig. 3). Out of consideration for the taxonomic position of the clade in the lineage, fungi may be regarded as on the border between highly communicative organisms and less complex ones.

\section{Functional evolution of sensory receptors}

Most physicochemical sensory receptors such as neurotransmitter receptors (Catapano \& Manji, 2007), photoreceptors (rhodopsin) (Hargrave et al., 1983), olfactory receptors (Buck \& Axel, 1991), gustatory receptors (Abe et al., 1993), vomeronasal receptors (Dulac \& Axel, 1995), and even mechanoreceptors (Makino et al., 2006) are 7-TMS proteins coupled with $\mathrm{G}$ protein for their molecular functions. Receptors with other signal-transducing mechanisms, including PDZ or EVH domain-containing partner, are also considered to be 7-TMS proteins (Bockaert \& Pin, 1999). Recently, the crystal structure of rhodopsin has been determined to show a seven-helix transmembrane structure (Palczewski et al.,
2000). On the other hand, the three-dimensional structures of membrane (cation) channels, such as the voltage-sensitive sodium channel, IP2R1, and canonical transient receptor potential-3 (TRPC3), have been also reconstructed by single-particle analysis from electron microscopic images and determined to have six transmembrane segments (Mio et al., 2008). Six-TMS proteins in prokaryotic membrane proteomes showed a characteristic pattern in membrane topology distribution (Fig. 4).

To scrutinize the functional distribution of animal membrane proteome GO functions in 7-TMS and 6-TMS proteins from $C$. familiaris, membrane proteome was examined with gene ontology using BLAST2GO (Conesa et al., 2005). Among the 6-TMS protein sequences annotated by the GO biological process, the proportion of protein members participating in molecular transportation was larger than $17 \%$, whereas there were about $1.8 \%$ in annotated $7-T M S$ protein sequences. The proteins involved in sensory perception, in contrast, constituted most of the annotated 7-TMS proteins (Figs. S1-S2 in supplementary material).

The superfamily of 7-TMS proteins is one of the largest such families in invertebrates and vertebrates including mammals (Bockaert \& Pin, 1999), and includes various receptors that recognize a great diversity of ligands, as mentioned above.

In vertebrates, the 7-TMS receptor gene family consists of hundreds of members, over $1 \%$ of the genome. For the olfactory receptor (OR), as an example of an inbound signal mediator, insect OR genes have been reported in fruit flies (Robertson et al., 2003), mosquitoes (Hill et al., 2002), and honey bees (Robertson and Wanner, 2006). Among the 62 Drosophila OR genes, atypical receptor OR83b is known to be highly conserved in amino acid sequence among different orders of insects (Krieger et al., 2003), and is coexpressed with 


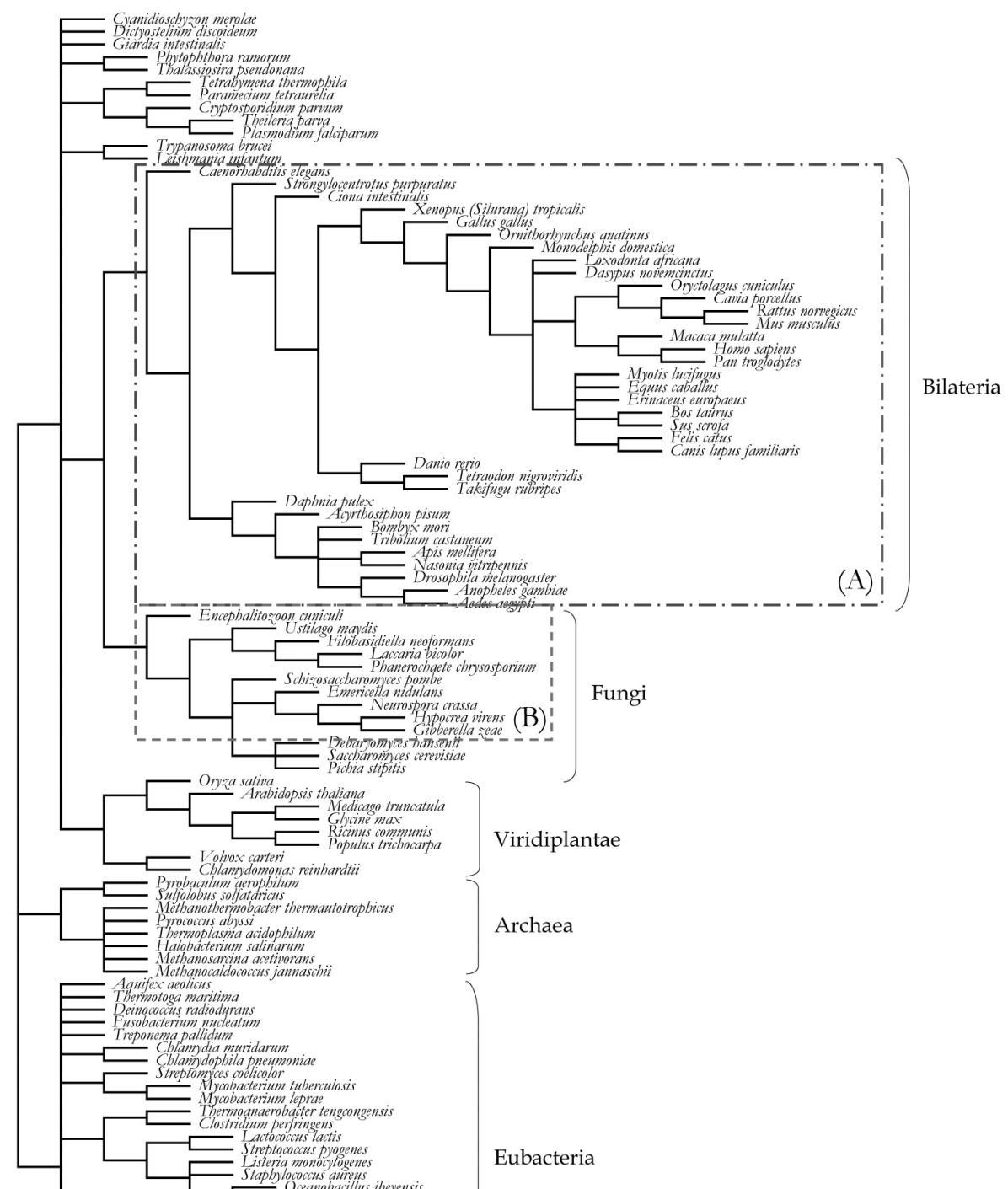

another OR gene in most olfactory receptor neurons (Larsson et al., 2004; Benton et al., 2006). It was thought to be conserved functionally across 250 million years of evolution in insects (Jones et al., 2005). However, chemosensory receptors such as olfactory and gustatory receptors in insects are not topologically close to GPCRs and are possibly more closely related to 6-TMS ion channels. They are known to possess inverted orientation to those of vertebrates and have the function of ligand-activated or cyclic-nucleotide-activated nonselective cation channels (Bargmann, 2006; Sato et al., 2008; Wicher et al. 2008). This could be a case of transient phenomenon in the di_erentiation and development of membrane proteins that have moved their main surmounting target from molecular barrier to information transmission. With the OR gene repertoire, we can see that motile multicellular organisms have evolved in accordance with their ecological circumstances (Table 3).

One possible explanation of this phenomenon is a combination of positive selection and purifying selection 


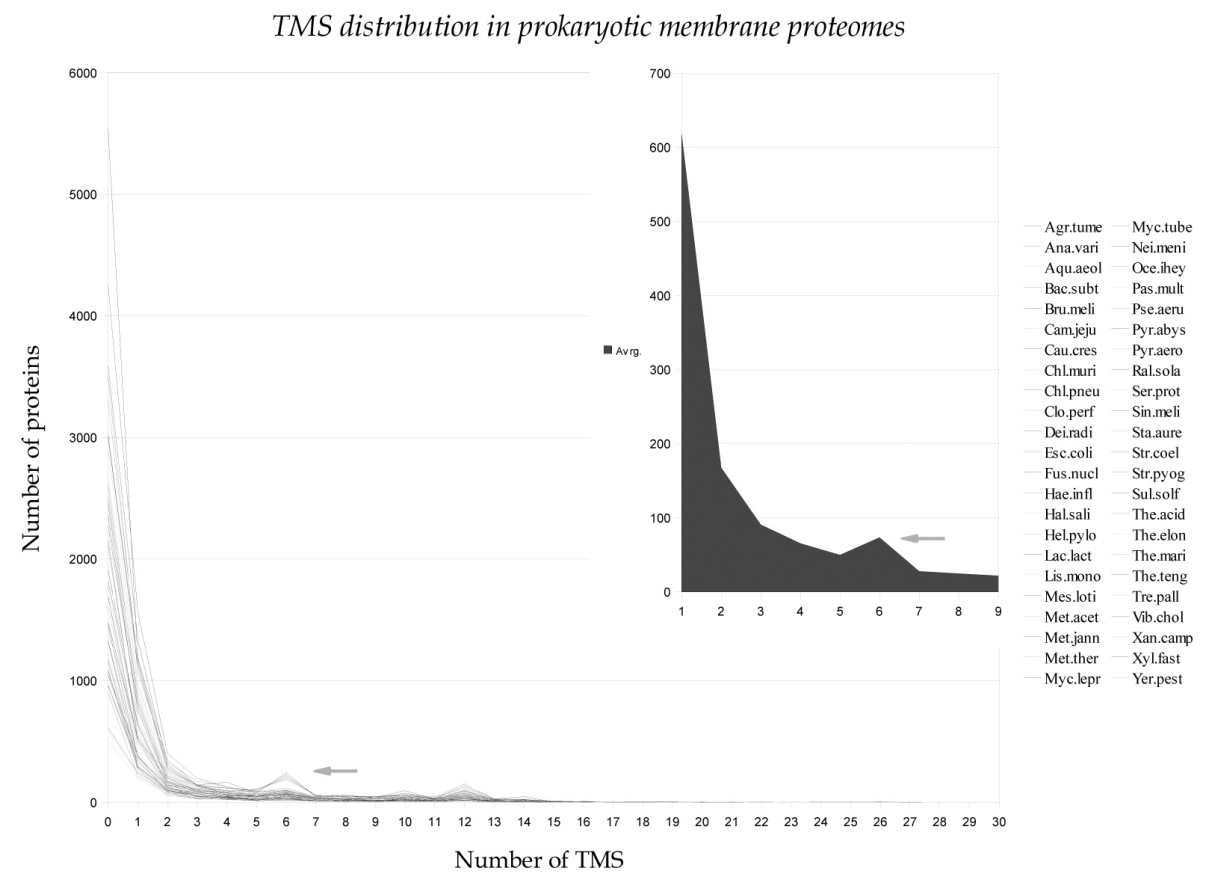

Fig. 4. TMS distribution in prokaryotic membrane proteomes. The numbers of 6-TMS proteins are indicated by green arrows. The small graph in dark blue shows the distribution pattern for the average values of the TMS numbers.
Table 3. Number of functional olfactory receptors in model organisms

\begin{tabular}{lcl}
\hline Species & No. of $\mathrm{OR}$ (func/total) & \multicolumn{1}{c}{ References } \\
\hline D. melanogaster & 62 & Robertson et al., (2003) \\
A. gambiae & 79 & Hill et al., (2002) \\
T. rubripes & $44 / 57$ & Alioto and Ngai, (2005) \\
D. rerio & $143 / 160$ & Alioto and Ngai, (2005) \\
G. gallus & $141 / 229$ & Lagerström et al., (2006) \\
C. familiaris & $872 / 1,094$ & Quignon et al., (2005) \\
M. musculus & $1,037 / 1,391$ & Niimura and Nei, (2005) \\
R. norvegicus & $1,201 / 1,493$ & Quignon et al., (2005) \\
M. mulatta & $309 / 606$ & Go and Niimura, (2008) \\
H. sapiens & $388 / 802$ & Niimura and Nei, (2005) \\
\hline
\end{tabular}

${ }^{*}$ Total means the sum of functional gene number and pseudogene number.

of membrane-signaling proteins. As organisms evolve, cellular information transfer becomes more complex and crucial than material transportation. In other words, as the signal-transducing system of an organism becomes more complex, the organism demands more participants such as various membrane receptors to operate its cellular signaling system to increase the organismal complexity. Simultaneously, when another function in an organism such as visionary ability improves, its olfactory ability retrogresses. An interesting fact is that almost all protein receptors participating and acting mainly in sensory systems are 7-TMS receptor proteins.

\section{Acknowledgments}

This work was supported by the 2006 Inje University research grant.

\section{Supplementary material}

Supplementary documents are attached to the manuscript.

\section{References}

Abe, K., Kusakabe, Y., Tanemura, K., Emori, Y., and Arai, S. (1993). Primary structure and cell-type specific expression of a gustatory $\mathrm{G}$ protein-coupled receptor related to olfactory receptors. J. Biol. Chem. 268, 12033- 12039.

Albert, R., Jeong, H., and Barabasi, A.-L. (1999). Diameter of the world-wide web. Nature 401, 130-131.

Bargmann, C. I. (2006). Comparative chemosensation from receptors to ecology. Nature 444, 295-301.

Benton, R., Sachse, S., Michnick, S. W., and Vosshall, L. B. (2006). Atypical membrane topology and heteromeric function of Drosophila odorant receptors in vivo. PLOS Biol. 4, e20.

Bockaert, J., and Pin, J. P. (1999). Molecular tinkering of G protein-coupled receptors: an evolutionary success. EMBO J. 18, 1723-1729.

Buck, L., and Axel, R. (1991). A novel multigene family may encode odorant receptors: a molecular basis for odor recognition. Cell 65, 175-187.

Catapano, L. A., and Manji, H. K. (2007). G protein-coupled receptors in major psychiatric disorders. Biochim. Biophys. Acta. 1768, 976-993. 
Conesa, A., Gtz, S., Garca-Gmez, J. M., Terol, J., Taln, M., and Robles, M. (2005). Blast2go: a universal tool for annotation, visualization and analysis in functional genomics research. Bioinformatics 21, 3674-3676.

Daley, D. O., Rapp, M., Granseth, E., Meln, K., Drew, D., and von Heijne, G. (2005). Global topology analysis of the Escherichia coli inner membrane proteome. Science 308, 1321-1323.

Dulac, C., and Axel, R. (1995). A novel family of genes encoding putative pheromone receptors in mammals. Cell 83, 195-206.

Hargrave, P. A., McDowell, J. H., Curtis, D. R., Wang, J. K., Juszczak, E., Fong, S. L., Rao, J. K., and Argos, P. (1983). The structure of bovine rhodopsin. Biophys Struct Mech 9, 235-244.

Harrison, P. M., and Gerstein, M. (2002). Studying genomes through the aeons: protein families, pseudogenes and proteome evolution. J. Mol. Biol. 318, 155-1174.

Hill, C. A., Fox, A. N., Pitts, R. J., Kent, L. B., Tan, P. L., Chrystal, M. A., Cravchik, A., Collins, F. H., Robertson, H. M., and Zwiebel, L. J. (2002). G protein-coupled receptors in anopheles gambiae. Science 298, 176-178.

Hong, X., Scofield, D. G., and Lynch, M. (2006). Intron size, abundance, and distribution within untranslated regions of genes. Mol. Biol. Evol. 23, 2392-2404.

Huynen, M. A., and van Nimwegen, E. (1998). The frequency distribution of gene family sizes in complete genomes. Mol. Biol. Evol. 15, 583-589.

Ikeda, M., Arai, M., Lao, D. M., and Shimizu, T. (2002). Transmembrane topology prediction methods: a re-assessment and improvement by a consensus method using a dataset of experimentally-characterized transmembrane topologies. In Silico Biol. 2, 19-33.

Ikeda, M., Arai, M., Okuno, T., and Shimizu, T. (2003). Tmpdb: a database of experimentally-characterized transmembrane topologies. Nucleic Acids. Res. 31, 406-409.

Inoue, Y., Yamazaki, Y., and Shimizu, T. (2005). How accurately can we discriminate $G$ protein-coupled receptors as 7-TMS TM protein sequences from other sequences? Biochem. Biophys, Res. Commun. 338, 1542-1546.

Jeong, H., Tombor, B., Albert, R., Oltvai, Z. N., and Barabsi, A. L. (2000). The large-scale organization of metabolic networks. Nature 407, 651-654.

Jones, W. D., Nguyen, T.-A. T., Kloss, B., Lee, K. J., and Vosshall, L. B. (2005). Functional conservation of an insect odorant receptor gene across 250 million years of evolution. Curr. Biol. 15, R119-R121.

Kim, H., Meln, K., Osterberg, M., and von Heijne, G. (2006). A global topology map of the Saccharomyces cerevisiae membrane proteome. Proc. Natl. Acad. Sci. U.S.A. 103, 11142-11147.

Krieger, J., Klink, O., Mohl, C., Raming, K., and Breer, $\mathrm{H}$. (2003). A candidate olfactory receptor subtype highly conserved across different insect orders. J. Comp. Physiol. A Neuroethol. Sens. Neural. Behav. Physiol. 189, 519-526.

Krogh, A., Larsson, B., von Heijne, G., and Sonnhammer, E. L. (2001). Predicting transmembrane protein topology with a hidden Markov model: application to complete genomes. J. Mol. Biol. 305, 567-580.
Larsson, M. C., Domingos, A. I., Jones, W. D., Chiappe, M. E., Amrein, H., and Vosshall, L. B. (2004). Or83b encodes a broadly expressed odorant receptor essential for Drosophila olfaction. Neuron 43, 703-714.

Li, W., and Kaneko, K. (1992). Long-range correlation and partial spectrum in a noncoding DNA sequence. Europhys. Lett. 17, 655-660.

Lynch, M., Scofield, D. G., and Hong, X. (2005). The evolution of transcription-initiation sites. Mol. Biol. Evol. 22, 1137-1146.

Makino, A., Prossnitz, E. R., Bnemann, M., Wang, J. M., Yao, W., and Schmid-Schnbein, G. W. (2006). G protein-coupled receptors serve as mechanosensors for fluid shear stress in neutrophils. Am J. Physiol. Cell. Physiol. 290, C1633-C1639.

Martignetti, L., and Caselle, M. (2007). Universal power law behaviors in genomic sequences and evolutionary models. Phys. Rev. E Stat. Nonlin. Soft Matter Phys. 76, 021902.

Mio, K., Ogura, T., and Sato, C. (2008). Structure of six-transmembrane cation channels revealed by single-particle analysis from electron microscopic images. J. Synchrotron Radiat. 15, 211-214.

Palczewski, K., Kumasaka, T., Hori, T., Behnke, C. A., Motoshima, H., Fox, B. A., Trong, I. L., Teller, D. C., Okada, T., Stenkamp, R. E., Yamamoto, M., and Miyano, M. (2000). Crystal structure of rhodopsin: A G protein-coupled receptor. Science 289, 739-745.

Peng, C. K., Buldyrev, S. V., Goldberger, A. L., Havlin, S., Sciortino, F., Simons, M., and Stanley, H. E. (1992). Long-range correlations in nucleotide sequences. Nature 356, 168-170.

Robertson, H. M., and Wanner, K. W. (2006). The chemoreceptor superfamily in the honey bee, Apis mellifera: expansion of the odorant, but not gustatory, receptor family. Genome Res. 16, 1395-1403.

Robertson, H. M., Warr, C. G., and Carlson, J. R. (2003). Molecular evolution of the insect chemoreceptor gene superfamily in Drosophila melanogaster. Proc. Natl. Acad. Sci. U.S.A. 100(Suppl 2), 14537-14542.

Sato, K., Pellegrino, M., Nakagawa, T., Nakagawa, T., Vosshall, L. B., and Touhara, K. (2008). Insect olfactory receptors are heteromeric ligand-gated ion channels. Nature 452, 1002-1006.

Tusnády, G. E., and Simon, I. (1998). Principles governing amino acid composition of integral membrane proteins: application to topology prediction. J. Mol. Biol. 283, 489-506.

Tusnády, G. E., and Simon, I. (2001). The HMMTOP transmembrane topology prediction server. Bioinformatics 17, 849-850.

Tusnády, G. E., and Simon, I. (2001). Topology of membrane proteins. J. Chem. Inf. Comput. Sci. 41, 364-368.

Voss, R. F. (1992). Evolution of long-range fractal correlations and $1 / f$ noise in DNA base sequences. Phys. Rev Lett. 68, 3805-3808.

Wallin, E., and von Heijne, G. (1998). Genome-wide analysis of integral membrane proteins from eubacterial, archaean, and eukaryotic organisms. Protein Sci. 7, 1029-1038.

Wicher, D., Schfer, R., Bauernfeind, R., Stensmyr, M. C., Heller, R., Heinemann, S. H., and Hansson, B. S. (2008). Drosophila odorant receptors are both ligand-gated and cyclic-nucleotide-activated cation channels. Nature 452, 1007-1011. 
118 Genomics \& Informatics Vol. 7(2) 111-121, June 2009

Table S1. List of selected species

\begin{tabular}{|c|c|c|c|c|c|c|c|}
\hline Species & Abbr. & Database & Domain & Species & Abbr. & Database & Domain \\
\hline Acyrthosiphon pisum & Acy.pisu & NCBI & Euk. & Takifugu rubripes & Tak,rubr & EnsEMBL & Euk. \\
\hline Aedes aegypti & Aed.aegy & EnsEMBL & Euk. & Tetraodon nigroviridis & Tet.nigr & EnsEMBL & Euk. \\
\hline Anopheles gambiae & Ano.gamb & EnsEMBL & Euk. & Tetrahymena thermophila & Tet.ther & JCVI & Euk. \\
\hline Apis mellifera & Api.mell & NCBI & Euk. & Thalassiosira pseudonana & Tha.pseu & JGI & Euk. \\
\hline Arabidopsis thaliana & Ara,thal & $\mathrm{NCBI}$ & Euk. & Theileria parva The. & parv & $\mathrm{NCBI}$ & Euk. \\
\hline Aspergillus nidulans & Asp.nidu & $\mathrm{NCBI}$ & Euk. & Tribolium castaneum & Tri.cast & $\mathrm{NCBI}$ & Euk. \\
\hline Bombyx mori & Bom. mori & SilkDB & Euk. & Trichoderma virens & Tri.vire & JGI & Euk. \\
\hline Bos taurus & Bos.taur & NCBI & Euk. & Trypanosoma brucei & Try.bruc & $\mathrm{NCBI}$ & Euk. \\
\hline Caenorhabditis elegans & Cae.eleg & EnsEMBL & Euk. & Ustilago maydis & Ust.mayd & $\mathrm{NCBI}$ & Euk. \\
\hline Canis familiaris & Can fami & EnsEMBL & Euk. & Volvox carteri & Vol.cart & JGI & Euk. \\
\hline Cavia porcellus & Cav.porc & EnsEMBL & Euk. & Xenopus tropicalis & Xen.trop & EnsEMBL & Euk. \\
\hline Chlamydomonas reinhardtii & Chl,rein & JGI & Euk. & Agrobacterium tumefaciens & Agr tume & $\mathrm{NCBI}$ & Prok. \\
\hline Ciona intestinalis & Cio.inte & $\mathrm{NCBI}$ & Euk. & Anabaena variabilis & Ana.vari & $\mathrm{NCBI}$ & Prok. \\
\hline Cryptococcus neoformans & Cry.neof & $\mathrm{NCBI}$ & Euk. & Aquifex aeolicus & Aqu.aeol & $\mathrm{NCBI}$ & Prok. \\
\hline Cryptosporidium parvum & Cry.parv & $\mathrm{NCBI}$ & Euk. & Bacillus subtilis & Bac.subt & $\mathrm{NCBI}$ & Prok. \\
\hline Cyanidioschyzon merolae & Cya.mero & U-Tokyo & Euk. & Brucella melitensis & Bru.meli & $\mathrm{NCBI}$ & Prok. \\
\hline Danio rerio & Dan.reri & $\mathrm{NCBI}$ & Euk. & Campylobacter jejuni & Cam.jeju & $\mathrm{NCBI}$ & Prok. \\
\hline Daphnia pulex & Dap.pule & JGI & Euk. & Caulobacter crescentus & Cau.cres & $\mathrm{NCBI}$ & Prok. \\
\hline Dasypus novemcinctus & Das.nove & EnsEMBL & Euk. & Chlamydia muridarum & Chl.muri & $\mathrm{NCBI}$ & Prok. \\
\hline Debaryomyces hansenii & Deb.hans & NCBI & Euk. & Chlamydophila pneumoniae & Chl.pneu & $\mathrm{NCBI}$ & Prok. \\
\hline Dictyostelium discoideum & Dic dics & $\mathrm{NCBI}$ & Euk. & Clostridium perfringens & Clo.perf & $\mathrm{NCBI}$ & Prok. \\
\hline Drosophila melanogaster & Dro.mela & EnsEMBL & Euk. & Deinococcus radiodurans & Dei,radi & $\mathrm{NCBI}$ & Prok. \\
\hline Encephalitozoon cuniculi & Enc.cuni & NCBI & Euk. & Escherichia coli & Esc.coli & $\mathrm{NCBI}$ & Prok. \\
\hline Equus caballus & Equ.caba & $\mathrm{NCBI}$ & Euk. & Fusobacterium nucleatum & Fus.nucl & $\mathrm{NCBI}$ & Prok. \\
\hline Erinaceus europaeus & Eri.euro & EnsEMBL & Euk. & Haemophilus influenzae & Hae.infl & $\mathrm{NCBI}$ & Prok. \\
\hline Felis catus & Fel.catu & EnsEMBL & Euk. & Halobacterium salinarum & Hal.sali & $\mathrm{NCBI}$ & Prok. \\
\hline Gallus gallus & Gal.gall & NCBI & Euk. & Helicobacter pylori & Hel.pylo & $\mathrm{NCBI}$ & Prok. \\
\hline Giardia lamblia & Gia.lamb & GiardiaDB & Euk. & Lactococcus lactis & Lac.lact & $\mathrm{NCBI}$ & Prok. \\
\hline Gibberella zeae & Gib.zeae & $\mathrm{NCBI}$ & Euk. & Listeria monocytogenes & Lis.mono & $\mathrm{NCBI}$ & Prok. \\
\hline Glycine max & Gly.max & JGI & Euk. & Mesorhizobium loti & Mes.loti & $\mathrm{NCBI}$ & Prok. \\
\hline Homo sapiens & Hom.sapi & $\mathrm{NCBI}$ & Euk. & Methanosarcina acetivorans & Met.acet & $\mathrm{NCBI}$ & Prok. \\
\hline Laccaria bicolor & Lac.bico & JGI & Euk. & Methanococcus jannaschii & Met.jann & $\mathrm{NCBI}$ & Prok. \\
\hline Leishmania infantum & Lei.infa & $\mathrm{NCBI}$ & Euk. & $\begin{array}{l}\text { Methanothermobacter } \\
\text { thermautotrophicus }\end{array}$ & Met.ther & $\mathrm{NCBI}$ & Prok. \\
\hline Loxodonta africana & Lox.afri & EnsEMBL & Euk. & Mycobacterium leprae & Myc.lepr & $\mathrm{NCBI}$ & Prok. \\
\hline Macaca mulatta & Mac.mula & EnsEMBL & Euk. & Mycobacterium tuberculosis & Myc.tube & NCBI & Prok. \\
\hline Medicago truncatula & Med.trun & Medicago.org & Euk. & Neisseria meningitidis & Nei.meni & NCBI & Prok. \\
\hline Monodelphis domestica & Mon.dome & NCBI & Euk. & Oceanobacillus iheyensis & Oce.ihey & NCBI & Prok. \\
\hline Mus musculus & Mus.musc & EnsEMBL & Euk. & Pasteurella multocida & Pas.mult & $\mathrm{NCBI}$ & Prok. \\
\hline Myotis lucifugus & Myo.luci & NCBI & Euk. & Pseudomonas aeruginosa & Pse.aeru & $\mathrm{NCBI}$ & Prok. \\
\hline Nasonia vitripennis & Nas.vitr & $\mathrm{NCBI}$ & Euk. & Pyrococcus abyssi & Pyr.abys & $\mathrm{NCBI}$ & Prok. \\
\hline Neurospora crassa & Neu.cras & $\mathrm{NCBI}$ & Euk. & Pyrobaculum aerophilum & Pyr.aero & $\mathrm{NCBI}$ & Prok. \\
\hline Ornithorhynchus anatinus & Orn.anat & NCBI & Euk. & Ralstonia solanacearum & Ral.sola & $\mathrm{NCBI}$ & Prok. \\
\hline Oryctolagus cuniculus & Ory.cuni & EnsEMBL & Euk. & Serratia proteamaculans & Ser.prot & $\mathrm{NCBI}$ & Prok. \\
\hline Oryza sativa & Ory.sati & NCBI & Euk. & Sinorhizobium meliloti & Sin.meli & NCBI & Prok. \\
\hline Pan troglodytes & Pan trog & EnsEMBL & Euk. & Staphylococcus aureus & Sta.aure & $\mathrm{NCBI}$ & Prok. \\
\hline Paramecium tetraurelia & Par.tetr & ParameciumDB & B Euk. & Streptococcus pyogenes & Str.pyog & $\mathrm{NCBI}$ & Prok. \\
\hline Phanerochaete chrysosporium & Pha.chry & JGI & Euk. & Streptomyces coelicolor & Str.coel & NCBI & Prok. \\
\hline Phytophthora ramorum & Phy.ramo & JGI & Euk. & Sulfolobus solfataricus & Sul.solf & $\mathrm{NCBI}$ & Prok. \\
\hline Pichia stipitis & Pic.stip & $\mathrm{NCBI}$ & Euk. & Thermoplasma acidophilum & The acid & $\mathrm{NCBI}$ & Prok. \\
\hline Plasmodium falciparum & Pla,falc & $\mathrm{NCBI}$ & Euk. & Thermosynechococcus elongatus & The.elon & $\mathrm{NCBI}$ & Prok. \\
\hline Populus trichocarpa & Pop.tric & JGI & Euk. & Thermotoga maritima & The.mari & $\mathrm{NCBI}$ & Prok. \\
\hline Rattus norvegicus & Rat.norv & EnsEMBL & Euk. & Thermoanaerobacter tengcongensis & sThe.teng & $\mathrm{NCBI}$ & Prok. \\
\hline Ricinus communis & Ric.comm & JCVI & Euk. & Treponema pallidum & Tre.pall & $\mathrm{NCBI}$ & Prok. \\
\hline Saccharomyces cerevisiae & Sac.cere & EnsEMBL & Euk. & Vibrio cholerae & Vib.chol & NCBI & Prok. \\
\hline Schizosaccharomyces pombe & Sch.pomb & NCBI & Euk. & Xanthomonas campestris & Xan.camp & $\mathrm{NCBI}$ & Prok. \\
\hline Strongylocentrotus purpuratus & Str.purp & $\mathrm{NCBI}$ & Euk. & Xylella fastidiosa & Xyl.fast & $\mathrm{NCBI}$ & Prok. \\
\hline Sus scrofa & Sus.scro & $\mathrm{NCBI}$ & Euk. & Yersinia pestis & Yer.pest & $\mathrm{NCBI}$ & Prok. \\
\hline
\end{tabular}


Table S2. List of selected public biological databases

\begin{tabular}{|c|c|c|}
\hline DB name & URL & remark \\
\hline EnsEMBL & ftp://ftp.ensembl.org/ & EnsEMBL $51^{[1]}$ \\
\hline GiardiaDB & http://giardiadb.org/ & CRITICA $^{[2]}$ and GLIMMER ${ }^{[3]}$ \\
\hline JCVI & ftp://ftp.jcvi.org/ & GLIMMER, $\mathrm{AAT}^{[4]}$, and PASA ${ }^{[5]}$ \\
\hline JGI & ftp://ftp.jgi-psf.org/ & DOE Joint Genome Institute \\
\hline Medicago.org & http://www.medicago.org/ & M. truncatula, IMGAG* \\
\hline NCBI & ftp://ftp.ncbi.nih.gov/ & including GNOMON ${ }^{[6]}$ \\
\hline ParameciumDB & http://paramecium.cgm.cnrs-gif.fr/ & P. tetraurelia, Genoscope $\mathrm{e}^{[7]}$ \\
\hline SilkDB & $\mathrm{ftp}: / / \mathrm{silkworm}, \mathrm{swu}$.edu.cn/ & B. mori, BGI Gene Finder ${ }^{[8]}$ \\
\hline U-Tokyo & http://merolae.biol.s.u-tokyo.ac.jp/ & C. merolae \\
\hline
\end{tabular}

*The International Medicago Genome Annotation Group

[1] P. Flicek, B. L. Aken, K. Beal, B. Ballester, M. Caccamo, Y. Chen, L. Clarke, G. Coates, F. Cunningham, T. Cutts, T. Down, S. C. Dyer, T. Eyre, S. Fitzgerald, J. Fernandez-Banet, S. Grf, S. Haider, M. Hammond, R. Holland, K. L. Howe, K. Howe, N. Johnson, A. Jenkinson, A. Khri, D. Keefe, F. Kokocinski, E. Kulesha, D. Lawson, I. Longden, K. Megy, P. Meidl, B. Overduin, A. Parker, B. Pritchard, A. Prlic, S. Rice, D. Rios, M. Schuster, I. Sealy, G. Slater, D. Smedley, G. Spudich, S. Trevanion, A. J. Vilella, J. Vogel, S. White, M.Wood, E. Birney, T. Cox, V. Curwen, R. Durbin, X. M. Fernandez-Suarez, J. Herrero, T. J. P. Hubbard, A. Kasprzyk, G. Proctor, J. Smith, A. Ureta-Vidal, S. Searle, Ensembl 2008., Nucleic Acids Res 36 (Database issue) (2008) D707-D714.

[2] J. H. Badger, G. J. Olsen, Critica: coding region identication tool invoking comparative analysis., Mol Biol Evol 16 (4) (1999) 512-524.

[3] A. L. Delcher, D. Harmon, S. Kasif, O. White, S. L. Salzberg, Improved microbial gene identication with glimmer., Nucleic Acids Res 27 (23) (1999) 4636-4641.

[4] X. Huang, M. D. Adams, H. Zhou, A. R. Kerlavage, A tool for analyzing and annotating genomic sequences., Genomics 46 (1) (1997) 37-45.

[5] B. Haas, S. Salzberg, W. Zhu, M. Pertea, J. Allen, J. Orvis, O. White, C. R. Buell, J. Wortman, Automated eukaryotic gene structure annotation using evidencemodeler and the program to assemble spliced alignments., Genome Biol 9 (1) (2008) R7.

[6] A. Nagy, H. Hegyi, K. Farkas, H. Tordai, E. Kozma, L. Bnyai, L. Patthy, Identication and correction of abnormal, incomplete and mispredicted proteins in public databases., BMC Bioinformatics 9 (2008) 353.

[7] J.-M. Aury, O. Jaillon, L. Duret, B. Noel, C. Jubin, B. M. Porcel, B. Sgurens, V. Daubin, V. Anthouard, N. Aiach, O. Arnaiz, A. Billaut, J. Beisson, I. Blanc, K. Bouhouche, F. Cmara, S. Duharcourt, R. Guigo, D. Gogendeau, M. Katinka, A.-M. Keller, R. Kissmehl, C. Klotz, F. Koll, A. L. Moul, G. Lepre, S. Malinsky, M. Nowacki, J. K. Nowak, H. Plattner, J. Poulain, F. Ruiz, V. Serrano, M. Zagulski, P. Dessen, M. Btermier, J. Weissenbach, C. Scarpelli, V. Schchter, L. Sperling, E. Meyer, J. Cohen, P. Wincker, Global trends of whole-genome duplications revealed by the ciliate paramecium tetraurelia., Nature 444 (7116) (2006) 171-178.

[8] Q. Xia, Z. Zhou, C. Lu, D. Cheng, F. Dai, B. Li, P. Zhao, X. Zha, T. Cheng, C. Chai, G. Pan, J. Xu, C. Liu, Y. Lin, J. Qian, Y. Hou, Z. Wu, G. Li, M. Pan, C. Li, Y. Shen, X. Lan, L. Yuan, T. Li, H. Xu, G. Yang, Y. Wan, Y. Zhu, M. Yu, W. Shen, D. Wu, Z. Xiang, J. Yu, J. Wang, R. Li, J. Shi, H. Li, G. Li, J. Su, X. Wang, G. Li, Z. Zhang, Q. Wu, J. Li, Q. Zhang, N. Wei, J. Xu, H. Sun, L. Dong, D. Liu, S. Zhao, X. Zhao, Q. Meng, F. Lan, X. Huang, Y. Li, L. Fang, C. Li, D. Li, Y. Sun, Z. Zhang, Z. Yang, Y. Huang, Y. Xi, Q. Qi, D. He, H. Huang, X. Zhang, Z. Wang, W. Li, Y. Cao, Y. Yu, H. Yu, J. Li, J. Ye, H. Chen, Y. Zhou, B. Liu, J. Wang, J. Ye, H. Ji, S. Li, P. Ni, J. Zhang, Y. Zhang, H. Zheng, B. Mao, W. Wang, C. Ye, S. Li, J. Wang, G. K.-S. Wong, H. Yang, B. A. Group, A draft sequence for the genome of the domesticated silkworm (bombyx mori)., Science 306 (5703) (2004) 1937-1940. 


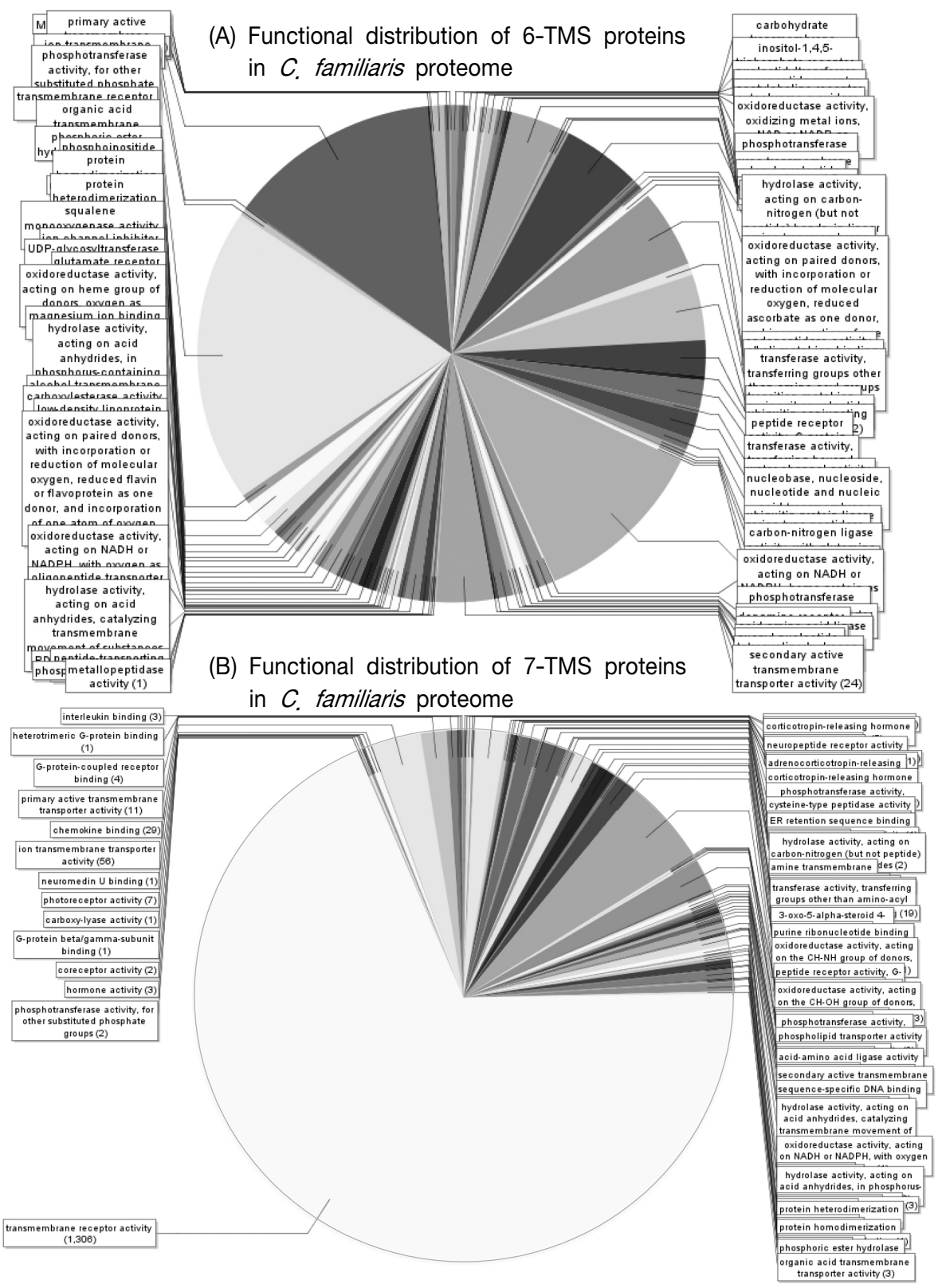

Fig. S1. Functional distributions of (A) 6-TMS and (B) 7-TMS proteins in $C$. familiaris produced by BLAST2GO molecular function at GO level 5. 
(A) Sequence distribution: biological_process (Fitered by \#Seqs: cutoff=5.0)

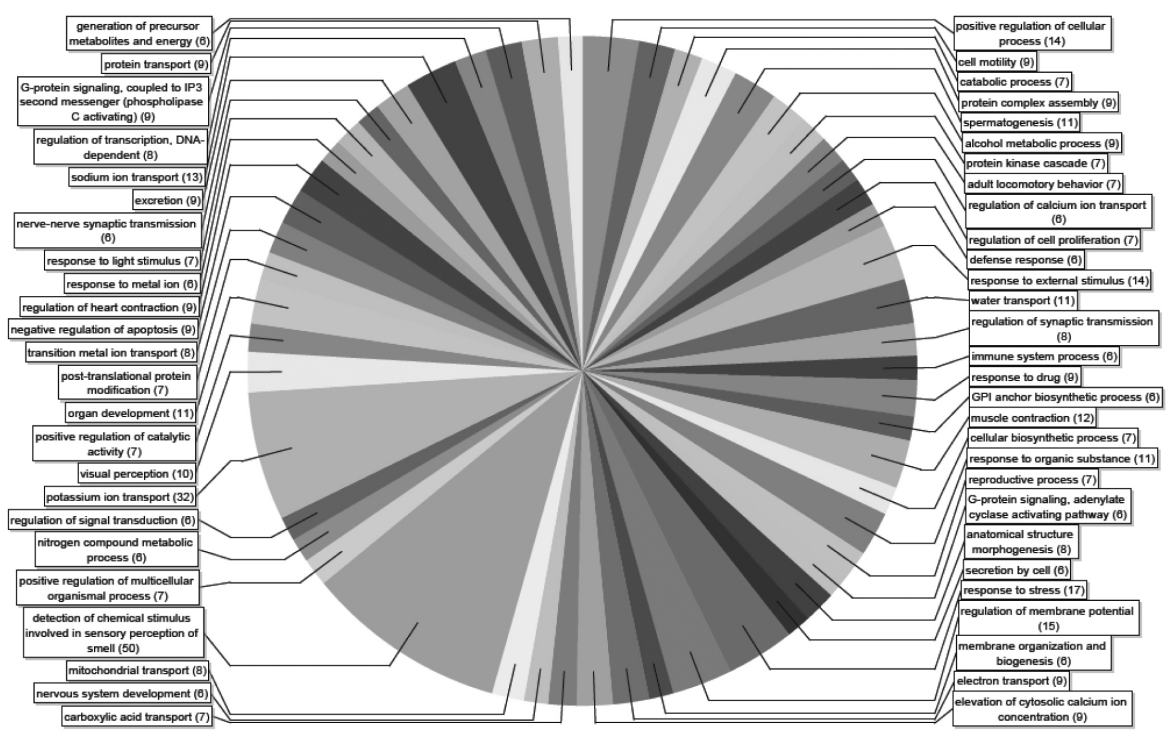

(B) Sequence distribution: biological_process (Filtered by \#Seqs: cutoff=5.0)

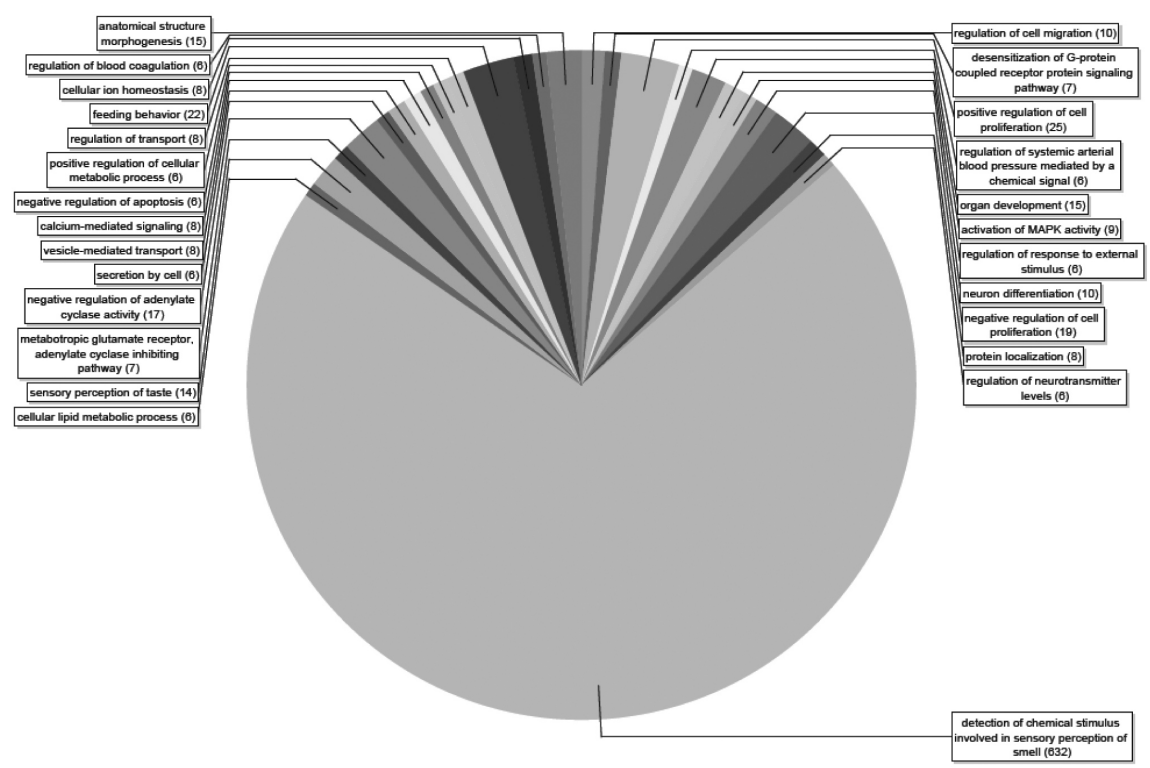

Fig. S2. Sequence distributions of (A) 6-TMS and (B) 7-TMS proteins in $C$. familiaris produced by BLAST2GO biological process. 